\title{
Outcome of proximal femoral nail antirotation in peritrochanteric fractures: A prospective study
}

\author{
Pratyenta Raj Onta', Dilip C Agarwal'2, Upendra Jung Thapa ${ }^{3}$, Pabin Thapa ${ }^{4}$, \\ Krishna Wahegoankar ${ }^{5}$, Niraj Ranjit ${ }^{6}$, Krishna Sapkota ${ }^{7}$ \\ ${ }^{1,3,4}$ Assistant Professor, ${ }^{2}$ Professor, ${ }^{5,6,7}$ Associate Professor, Department of Orthopedics, Manipal Teaching Hospital
}

Background: The incidence of peritrochanteric fractures are increasing worldwide. Early mobilization in these fractures prevents from other medical complications. There are many methods of treatment but the ideal method should be less invasive procedure, intramedullary device and stable fixation of fracture. Proximal femoral nail antirotation (PFNA) is biomechanically considered one of the most effective methods of treatment with promising results. Aims and Objectives: The aim of our study was to evaluate the clinical and radiological outcomes in patient who were treated with PFNA in peritrochanteric fracture. Materials and Methods: This study was a prospective study which included 37 patients, conducted in Manipal Teaching Hospital from $1^{\text {st }}$ October 2019 to $30^{\text {th }}$ September 2020. All the patients were clinically evaluated and detail history was obtained. After the anaesthesia clearance the patients were operated. Operating time, intraoperative blood loss and complications were noted. Postoperatively the duration of hospital stay, time of partial and full weight bearing, time for radiological union and complications were noted. At the final follow up Harris Hip Score was used for functional outcome. Results: The mean age of the patient in this study was 64 years (45-88 years). The average time to complete the surgery was 62.49 minutes (45-75 minutes) and the average blood loss was $129.32 \mathrm{ml}(65$ $210 \mathrm{ml}$ ). Partial weight bearing was started at the mean time of 8.57 weeks (6-12 weeks) whereas full weight bearing was done at the mean of 14.43 weeks (10-20 weeks). Fracture union was seen at the average of 11.41 weeks (8-18 weeks). The mean Harris Hip score at final follow up was $84.73(65.8-95.0)$ with the functional status of $35.1 \%$ excellent result, $45.9 \%$ good, $13.5 \%$ fair and $5.4 \%$ poor. Conclusion: Proximal femoral nail antirotation in peritrochanteric fracture is a good method of fixation. The procedure is easy with reduced operative time and radiation exposure. Since this is minimally invasive procedure the blood loss is very less compared to DHS or plate fixation. The patient could be mobilized early from the bed that reduced the complication of immobilization. So we strongly recommend using PFNA for fixation of peritrochanteric fracture of hip.

Access this article online

Website:

http://nepjol.info/index.php/AJMS DOI: 10.3126/ajms.v12i8.36401

E-ISSN: 2091-0576

P-ISSN: 2467-9100

Copyright (c) 2021 Asian Journal of Medical Sciences

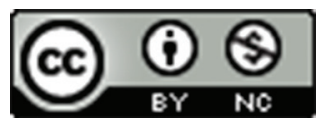

This work is licensed under a Creative Commons Attribution-NonCommercial 4.0 International License.

Key words: Hip fracture; Osteoporosis; Proximal femoral nail antirotation

\section{INTRODUCTION}

Peritrochanteric fractures mainly comprises fracture of trochanteric and subtrochanteric region and are considered as devastating injuries that mostly affects geriatric age group due to osteoporosis and in younger population mainly due to high velocity trauma. With the increase in life expectancy the incidence of such fractures are increased. ${ }^{1}$ To prevent the dreaded complications due to immobilization early mobility becomes the primary goal of treatment. ${ }^{2}$ Stable fixation that allows early mobilization is the aim of management in peritrochanteric fractures. ${ }^{3}$

Implants used in fixation of peritrochanteric fracture can be divided into two groups - extramedullary and intramedullary devices. Extramedullary device consists 
of dynamic hip screw (DHS), dynamic condylar screw and proximal femoral plate whereas intramedullary device consists of proximal femur nail, gamma nail and proximal femoral nail antirotation. DHS introduced in 1964 allowed for controlled compression at fracture site was most commonly used extramedullary devices for the treatment of hip fractures. ${ }^{4}$ DHS has its disadvantages like relatively large exposure, significant soft tissue stripping and anatomical reduction. Additionally, the screws and side plate create stress risers in the bone that can increase the risk of fracture distal to the implant. ${ }^{5}$ Studies have reported that the sliding hip screw is not ideal for unstable peritrochanteric fractures. ${ }^{6,7}$

The ideal implant for the treatment of peritrochanteric fractures should be easily inserted intramedullary device that allows for controlled impaction across the fracture zone while preventing fracture site rotation. ${ }^{8}$ Intramedullary implants withstand higher static and several fold higher cyclical loading than the DHS type of implant. In 1998 proximal femoral nail (PFN) was introduced with proximal de-rotation screw and distal lag screw. PFN had better fixation as compared to extramedullary device but there were complications like screw cut out, varus collapse, screw migration and $Z$ effect. ${ }^{9}$ In 2004, the proximal femoral nail antirotation (PFNA) developed by the AO/ ASIF group was introduced as a one of the modern generation intramedullary nails. The unique characteristic of this implant is the use of a single helical blade with a large surface area instead of screw. The inserted blade achieves an excellent fit through bone compaction and requires less bone removal compared with a screw. The helical blade allows better purchase in the femoral head to limit cut-outs due to varus deviation and rotation. This feature provides optimal anchoring and stability especially, when inserted into osteoporotic bone and has been biomechanically proven to retard rotation and varus collapse. ${ }^{10}$ Biomechanical studies have proved PFNA as one of the most effective methods in the treatment of peritrochanteric femur fractures. ${ }^{11-13}$

The aim of this study is to evaluate radiographic and functional outcomes of proximal femoral nail antirotation (PFNA) in peritrochanteric fractures and to assess intra-and postoperative complications of PFNA.

\section{MATERIALS AND METHODS}

This was a prospective study with 42 patients who were treated with PFNA from $1^{\text {st }}$ October 2019 to $30^{\text {th }}$ September 2020 in Manipal Teaching Hospital. All patients with peritrochanteric fracture who underwent PFNA within the study period were included in the study (Census sampling).
We lost follow up in 5 patients who were excluded from the study. So the total numbers of patients were 37 till the last follow-up. Ethical clearance from IRC of Manipal College of Medical Sciences and Manipal Teaching Hospital was obtained prior to the study. All patients were informed about the operative procedure and written consent was obtained. The inclusion and exclusion criteria of the study were as follows.

\section{Inclusion criteria}

1. Skeletally matured bone.

2. Fracture due to trauma.

3. Fracture within 21 days of injury.

4. Normal hip and knee movement before injury.

5. Ability to walk prior to injury.

\section{Exclusion criteria}

1. Physis not closed.

2. Pathological fracture.

3. Previous hip surgeries.

4. Isolated or combined medial femoral neck fracture.

5. Open fracture.

6. Loss of follow up.

\section{Clinical assessment}

Detailed history of all patients including mechanism of injury was taken. Preoperative medical evaluation and clearance from anaesthesia team was taken. Intraoperative information including operative time, blood loss and length of hospital stay were recorded for each patient. Any intra operative and post-operative complications were recorded. Time for partial weight bearing and full weight bearing in all patients were recorded. At final follow up Harris Hip score was used to access the functional outcome.

\section{Surgical method}

After anesthesia all the patients were kept in fracture table. Reduction of fracture was done under image guidance. The affected limb was kept $10-15^{\circ}$ of abduction for easy nail insertion. Tip of greater trochanter was identified and skin incision was made $5 \mathrm{~cm}$ proximally. Bone awl was used to make the entry point at the tip of trochanter and guide wire was inserted. The position of wire was checked in image in both AP and lateral view. The soft tissue was protected and intramedullary reaming was done using flexible reamers. The appropriate diameter and length of nail was attached to the insertion handle and inserted into the femur. The guide wire was removed. The $130^{\circ}$ aiming arm was attached to the insertion handle and guide wire for helical blade was inserted through small lateral incision. Central position of blade guide wire in both AP and lateral view was checked. The length of helical blade was measured and the cortex was drilled with $11 \mathrm{~mm}$ cannulated reamer. The appropriate size helical blade was inserted over guide wire by gentle 
blow with hammer and locked by turning the impactor clockwise. The distal locking of nail was done. Closure of the wound was done by standard technique.

Quadriceps exercise and knee ROM was started from first postoperative day. First dressing was done on $3^{\text {rd }}$ postoperative day and sutures were removed on $14^{\text {th }}$ postoperative day. Patient was mobilized non weight bearing in walker or crutches. Patient was followed up at the interval of 1, 3 and 6 months. Harris hip score (HHS) was used for functional outcome at final follow up. SPSS package version 23.0.0 was used for calculation of data. The final results were discussed and conclusion was made.

\section{RESULTS}

The mean age of the patient in this study was 64 years \pm 10.324 (45-88 years). Females were mostly affected 21 cases $(56.8 \%)$. Right side was commonly fractured and trivial injury like fall from standing height; fall from bed etc. was the commonest mechanism. Classification of fracture was done using $\mathrm{AO}$ classification, 16 patients $(43.2 \%)$ had $31 \mathrm{~A} 3$, 13 patients $(35.1 \%)$ had $31 \mathrm{~A} 2$ in and 8 patients $(21.6 \%)$ had 31A1 type fracture as in Table 1.

The average duration of hospital stay was 8.46 days \pm 3.5 (5-14 days). The average time to complete the operative procedure was 62.49 minutes \pm 8.3 (45-75 minutes). The average operative time for A1 fracture was $59.5 \pm 8.01$ minutes, for A2 it was $64.77 \pm 7.49$ and for A3 it was $62.12 \pm 9.03$ minutes ( $\mathrm{p}$ value 0.83 ), which was statically insignificant. The mean intraoperative blood loss was $129.32 \mathrm{ml} \pm 42.69(65-210 \mathrm{ml})$. The average blood loss in $\mathrm{A} 1, \mathrm{~A} 2$ and $\mathrm{A} 3$ fractures were $125.62 \pm 41.18 \mathrm{ml}, 135 \pm 40.1$ $\mathrm{ml}$ and $126.56 \pm 47.45 \mathrm{ml}$ respectively with $\mathrm{p}$ value 0.70 which showed the intraoperative blood loss did not vary upon the fracture pattern. There was increase in blood loss with increase in operative time which was statistically significant with $\mathrm{p}$ value of 0.047 . Only 7 patients $(18.9 \%)$ required post-operative blood transfusion as in Table 2 .

Partial weight bearing was started at an average of 8.57 weeks \pm 2.03 (6-12 weeks) whereas full weight bearing was started at 14.43 weeks \pm 3.13 (10-20 weeks). Callus was seen on an average of $11.41 \pm 2.69$ weeks (8-18 weeks). Post operatively 12 patients $(32.4 \%)$ required walking aids for mobilization. Quality of reduction of fracture was good in 21 patient $(56.8 \%)$, fair in $13(35.1 \%)$ and poor in 3 patients $(8.1 \%)$. Similarly the position of implant was optimal in 34 cases $(91.9 \%)$ and suboptimal in 3 cases $(8.1 \%)$.

The mean Harris Hip Score (HHS) at the final follow up was $84.73 \pm 7.55$ points (65.8-95.0), it was $90.95 \pm 2.38$ in A1 fracture, $83.13 \pm 2.38$ in $\mathrm{A} 2$ and $82.93 \pm 8.84$ points in $\mathrm{A} 3$

\begin{tabular}{lc}
\multicolumn{3}{l}{ Table 1: Patient demography } \\
\hline Age & \\
Sex & $\pm 10.324(45-88$ years $)$ \\
Male & $16(43.5 \%)$ \\
Female & $21(56.8 \%)$ \\
Side & \\
$\quad$ Right & $21(56.8 \%)$ \\
$\quad$ Left & $16(43.2 \%)$ \\
Mechanism of Injury & \\
Trivial injury & $16(43.2 \%)$ \\
Fall from height & $12(32.4 \%)$ \\
RTA & $9(24.4 \%)$ \\
AO type & \\
31A1 & $8(21.6 \%)$ \\
31A2 & $13(35.1 \%)$ \\
31A3 & $16(43.2 \%)$ \\
\hline
\end{tabular}

\begin{tabular}{lc} 
Table 2: Operative details \\
\hline Operative duration & 62 minutes $\pm 8.3(45-75$ minutes $)$ \\
Blood loss & $127 \mathrm{ml} \pm 34.86(85-210 \mathrm{ml})$ \\
Blood transfusion & $7(18.9 \%)$ \\
$\quad$ Required & $30(81.1 \%)$ \\
$\quad$ Not required & 8.46 days $+3.5(5-14$ days $)$ \\
\hline
\end{tabular}

with no significance difference ( $p$ value 0.06 ) as described in Table 3 . The average limb length discrepancy was $0.52 \mathrm{cms}$ $\pm 0.73(0-2 \mathrm{~cm})$. The functional status according to HHS showed excellent result in 13 patients $(35.1 \%)$, good in 17 patients (45.9\%), fair in 5 patients $(13.5 \%)$ and poor in 2 patients (5.4\%). All patients in our study had union of fracture and there were no major complications. Four $(10.81 \%)$ patients developed outer thigh pain and $1(2.7 \%)$ developed decubitus ulcer.

\section{DISCUSSION}

Peritrochanteric fracture is commonly seen in elderly people. Stable operative fixation allows early mobilization and also prevents from other medical complications. PFNA is a promising intramedullary implant that was developed for better fixation for unstable peritrochanteric fracture in osteoporotic bone.

The mean operative time in our study was 62 minutes. It was 59.5 minutes in patients with A1 type fracture and 64.77 and 62.12 in A2 and A3 type fracture respectively. In the study done by Bananh et al., and Simmermacher $\mathrm{R}$ $\mathrm{K}$ et al., the mean operative time were 68 and 67 minutes respectively. ${ }^{14,15}$ The average volume of blood loss in our study was $129 \mathrm{ml}$. It was found that increase in operative time leads to increase in blood loss which was statically significant ( $p$ value 0.047 ).

Aguado-Maestro et al., studied 200 patients with peritrochanteric fracture managed with PFNA and found 
Table 3: Intraoperative and Post-operative clinical data

\begin{tabular}{lccccc} 
Headings & All patients & AO31A1 & A031A2 & A031A3 & p value \\
\hline Operative procedure (minutes) & $62.49 \pm 8.13$ & $59.5 \pm 8.01$ & $64.77 \pm 7.49$ & $62.12 \pm 9.03$ & 0.83 \\
Blood loss (ml) & $129.32 \pm 42.69$ & $125.62 \pm 41.18$ & $135 \pm 40.10 \mathrm{ml}$ & $126.56 \pm 47.45$ & 0.70 \\
Partial weight bearing (weeks) & $8.57 \pm 2.03$ & $8.75 \pm 2.12$ & $8.69 \pm 2.32$ & $8.38 \pm 1.85$ & 0.52 \\
Full weight bearing (weeks) & $14.43 \pm 3.13$ & $14.62 \pm 3.46$ & $14.46 \pm 3.45$ & $14.31 \pm 2.89$ & 0.88 \\
Harris hip score & $84.73 \pm 7.55$ & $90.95 \pm 2.38$ & $83.13 \pm 6.09$ & $82.93 \pm 8.84$ & 0.06 \\
\hline
\end{tabular}

that the incidence of helical blade cut out to be $1 \%$ similarly the study done by Sahin et al., and Zhang et al., the incidence was $4.7 \%$ and $7.9 \%$ respectively. ${ }^{16-18}$ In our study we did not find any case with helical blade cut out. Femoral head perforation is one of the complications encountered with the use of PFNA. The reported incidence of femoral head perforation were $1.4 \%$ in the study done by Karapinar et al., and $1.2 \%$ by Simmermarcher et al. ${ }^{19,20}$ The helical blade cut out and femoral head perforation are the long term complications. We might have missed these complications due to short duration follow up in our study

At final follow up Harris hip score was used to evaluate the functional status which showed excellent result in 35.1\% cases, good in $45.9 \%$, fair in $13.5 \%$ and poor in $5.4 \%$ which was similar to the result done by Harshwardhan $\mathrm{H}$ et al., which was excellent in 30\%, good in 40\% fair in 20\% and poor in $10 \%{ }^{21}$ The mean HHS in our study was $84.73 \pm 7.55$ points which was similar to the study done by Liu et al (84) and Kashid et al (88.48). ${ }^{22,23}$ This shows that the PFNA has good functional outcome and should be used in patients with peritrochanteric fractures.

\section{Limitation of study}

The number of cases in this study was small. The duration of follow up was short and could have been done to 1 year which could show long term efficacy. The study could have been better if it was compared to other modalities of treatments. Hence large sample multicenter study is required.

\section{CONCLUSION}

Proximal femoral nail antirotation in peritrochanteric fracture is a good method of fixation. The procedure is easy with reduced operative time and radiation exposure. Since this is minimally invasive procedure the blood loss is very less compared to DHS or plate fixation. The patient could be mobilized early from the bed that reduced the complication of immobilization. So we strongly recommend using PFNA for fixation of peritrochanteric fracture of hip.

\section{REFERENCES}

1. Xu YZ, Geng DC, Mao HQ, Zhu XS and Yang HL. A comparison of the proximal femoral nail antirotation device and dynamic hip screw in the treatment of unstable pertrochanteric fracture.
Journal of International Medical Research. 2010; 38(4):12661275.

https://doi.org/10.1177/147323001003800408

2. Handoll $\mathrm{HH}$ and Parker MJ. Conservative versus operative treatment for hip fractures in adults. Cochrane database of systematic reviews. 2008(3).

https://doi.org/10.1002/14651858.CD000337.pub2

3. Lavelle DG. Fractures and dislocations of the hip. Edited by: Canale ST. Campbell's Operative Orthopedics. Philadelphia: Mosby-Elsevier. 2008:3237-308.

https://doi.org/10.1016/B978-0-323-03329-9.50055-6

4. Pajarinen J, Lindahl J, Michelsson $O$, Savolainen $V$ and Hirvensalo E. Pertrochanteric femoral fractures treated with a dynamic hip screw or a proximal femoral nail: a randomised study comparing post-operative rehabilitation. The Journal of bone and joint surgery. British volume. 2005; 87(1):76-81.

https://doi.org/10.1302/0301-620X.87B1.15249

5. Kim WY, Han $\mathrm{CH}$, Park JI and Kim JY. Failure of intertrochanteric fracture fixation with a dynamic hip screw in relation to preoperative fracture stability and osteoporosis. International orthopaedics. 2001; 25(6):360-362.

https://doi.org/10.1007/s002640100287

6. Haidukewych GJ, Israel TA and Berry DJ. Reverse obliquity fractures of the intertrochanteric region of the femur. JBJS. 2001; 83(5):643-650.

https://doi.org/10.2106/00004623-200105000-00001

7. Carulli C, Piacentini F, Paoli T, Civinini R and Innocenti M. A comparison of two fixation methods for femoral trochanteric fractures: a new generation intramedullary system vs sliding hip screw. Clinical Cases in Mineral and Bone Metabolism. 2017; 14(1):40.

https://doi.org/10.11138/ccmbm/2017.14.1.041

8. Sommers MB, Roth C, Hall H, Kam BC, Ehmke LW, Krieg JC, et al. A laboratory model to evaluate cutout resistance of implants for pertrochanteric fracture fixation. Journal of Orthopaedic Trauma. 2004; 18(6):361-368.

https://doi.org/10.1097/00005131-200407000-00006

9. Hohendorff B, Meyer P, Menezes D, Meier L and Elke R. Treatment results and complications after PFN osteosynthesis. Der Unfallchirurg. 2005; 108(11):938-940.

https://doi.org/10.1007/s00113-005-0962-8

10. Mereddy $\mathrm{P}$, Kamath $\mathrm{S}$, Ramakrishnan $\mathrm{M}$, Malik $\mathrm{H}$ and Donnachie N. The AO/ASIF proximal femoral nail antirotation (PFNA): a new design for the treatment of unstable proximal femoral fractures. Injury. 2009; 40(4):428-432.

https://doi.org/10.1016/j.injury.2008.10.014

11. Gardenbroek TJ, Segers MJ, Simmermacher RK and Hammacher ER. The proximal femur nail antirotation: an identifiable improvement in the treatment of unstable pertrochanteric fractures? Journal of Trauma and Acute Care Surgery. 2011; 71(1):169-174. https://doi.org/10.1097/TA.0b013e3182213c6e

12. Gavaskar AS, Subramanian M and Tummala NC. Results of 
proximal femur nail antirotation for low velocity trochanteric fractures in elderly. Indian Journal of Orthopaedics. 2012; 46:556-560.

https://doi.org/10.4103/0019-5413.101036

13. Kraus M, Krischak G, Wiedmann K, Riepl C, Gebhard F, Jöckel JA, et al. Clinical evaluation of PFNA® and relationship between the tip-apex distance and mechanical failure. Der Unfallchirurg. 2011; 114(6):470-478.

https://doi.org/10.1007/s00113-011-1975-0

14. Banan H, Al-Sabti A, Jimulia $T$ and Hart AJ. The treatment of unstable, extracapsular hip fractures with the AO/ASIF proximal femoral nail (PFN)-our first 60 cases. Injury. 2002; 33(5):401-405. https://doi.org/10.1016/S0020-1383(02)00054-2

15. Simmermacher RK, Bosch $\mathrm{AM}$ and Van der Werken $\mathrm{CH}$. The AO/ASIF-proximal femoral nail (PFN): a new device for the treatment of unstable proximal femoral fractures. Injury. 1999;30(5):327-332.

https://doi.org/10.1016/S0020-1383(99)00091-1

16. Aguado-Maestro I, Escudero-Marcos R, García-García JM, Alonso-García N, Pérez-Bermejo D, Aguado-Hernández HJ, et al. Results and complications of pertrochanteric hip fractures using an intramedullary nail with a helical blade (proximal femoral nail antirotation) in 200 patients. Revista Española de CirugíaOrtopédica y Traumatología (English Edition). 2013; 57(3):201-207.

https://doi.org/10.1016/j.recote.2013.03.005

17. Şahin EK, Imerci A, Kınık H, Karapınar L, Canbek $U$ and Savran A. Comparison of proximal femoral nail antirotation (PFNA) with AO dynamic condylar screws (DCS) for the treatment for unstable peritrochanteric femoral fractures. European Journal of Orthopaedic Surgery and Traumatology. 2014; 24(3):347-352.

https://doi.org/10.1007/s00590-013-1195-0
18. Zhang $H$, Zhu X, Pei G, Zeng X, Zhang N, Xu P, et al. A retrospective analysis of the InterTan nail and proximal femoral nail anti-rotation in the treatment of intertrochanteric fractures in elderly patients with osteoporosis: a minimum follow-up of 3 years. Journal of Orthopaedic Surgery and Research. 2017; 12(1):1-8.

https://doi.org/10.1186/s13018-017-0648-2

19. Karapinar L, Kumbaraci M, Kaya A, Imerci A and Incesu M. Proximal femoral nail anti-rotation (PFNA) to treat peritrochanteric fractures in elderly patients. European Journal of Orthopaedic Surgery and Traumatology. 2012; 22(3):237-243. https://doi.org/10.1007/s00590-011-0810-1

20. Simmermacher RK, Ljungqvist $J$, Bail $H$, Hockertz $T$, Vochteloo AJ, Ochs $U$, et al. The new proximal femoral nail antirotation (PFNA $\AA$ ) in daily practice: results of a multicentre clinical study. Injury. 2008; 39(8):932-939. https://doi.org/10.1016/j.injury.2008.02.005

21. Harshwardhan $\mathrm{H}$, Jain $\mathrm{S}$ and Sharma M. An outcome analysis of intertrochanteric fracture of femur managed with proximal femoral nail antirotation II. International Journal of Research in Orthopedics. 2019; 5(4):699-702.

https://doi.org/10.18203/issn.2455-4510.IntJResOrthop 20192687

22. Liu Y, Tao R, Liu F, Wang Y, Zhou Z, Cao Y, et al. Mid-term outcomes after intramedullary fixation of peritrochanteric femoral fractures using the new proximal femoral nail antirotation (PFNA). Injury. 2010; 41(8):810-817. https://doi.org/10.1016/j.injury.2010.03.020

23. Kashid MR, Gogia T, Prabhakara A, Jafri MA, Shaktawat DS and Shinde G. Comparative study between proximal femoral nail and proximal femoral nail antirotation in management of unstable trochanteric fractures. Int J Res Orthop. 2016; 2(4):354-358. https://doi.org/10.18203/issn.2455-4510.IntJResOrthop20164168

\footnotetext{
Author's contribution:

PRO- Concept and design, review of literature, statistically analysis and interpretation, manuscript preparation and revision; DCA- Correction, data analysis and manuscript review; NR- Data collection and manuscript revision; KW- Manuscript revision and literature review; KS- Literature search and review; PT- Literature search and review; UJT- Data collection, statistically analysis and literature review.

Work attributed to:

Department of Orthopedics, Manipal Teaching Hospital, Phulbari, Pokhara, Nepal.

Orcid ID:

Dr. Pratyenta Raj Onta- (i) https://orcid.org/0000-0002-6013-4014

Dr. Upendra Jung Thapa- (1) https://orcid.org/0000-0003-1980-5610

Dr. Pabin Thapa- (i) https://orcid.org/0000-0003-1336-5837

Dr. Krishna Wahegaonkar- (1) https://orcid.org/0000-0001-7274-7099

Dr. Niraj Ranjeet- (1) https://orcid.org/0000-0001-5460-5839

Dr. Krishna Sapkota- (1) https://orcid.org/0000-0002-2277-8556

Source of Funding: None, Conflict of Interest: None.
} 